\title{
The association between occurrence and severity of subclinical and clinical mastitis on pregnancies per artificial insemination at first service of Holstein cows
}

\author{
M. J. Fuenzalida, P. M. Fricke, and P. L. Ruegg ${ }^{1}$ \\ Department of Dairy Science, University of Wisconsin, Madison 53706
}

\begin{abstract}
The objective of this prospective study was to determine associations between occurrence and severity of clinical (CM) and subclinical mastitis (SM) during a defined breeding risk period (BRP, $3 \mathrm{~d}$ before to $32 \mathrm{~d}$ after artificial insemination) on pregnancies per artificial insemination at first service (P/AI1). Dairy cows ( $\mathrm{n}=$ 3,144 ) from 4 Wisconsin herds were categorized based on the occurrence of one or more $\mathrm{CM}$ or SM events during and before the BRP: (1) healthy, (2) mastitis before BRP, (3) SM during BRP, (4) chronic SM, (5) CM during BRP, or (6) chronic CM. Clinical mastitis cases were categorized based on etiology (gram-negative, gram-positive, and no growth) and severity (mild, moderate, or severe). Compared with healthy cows, the odds of pregnancy were $0.56,0.67$, and 0.75 for cows experiencing chronic CM, CM, or SM during the BRP, respectively. The occurrence of chronic SM was not associated with reduced probability of P/AI1. Compared with healthy cows, the odds of pregnancy were 0.71 and 0.54 for cows experiencing mild or moderate-severe cases of CM during the BRP, respectively. The odds of pregnancy for cows experiencing CM caused by gramnegative or gram-positive bacteria during the BRP were 0.47 and 0.59 , respectively. The occurrence of CM that resulted in no growth of bacteria in cultured milk samples was not associated with reductions in P/AI1. Regardless of etiology, microbiologically positive cases of $\mathrm{CM}$ with moderate or severe symptoms were associated with substantial reductions in P/AI1. Etiology, severity, and timing of CM were associated with decreases in the probability of pregnancy at first artificial insemination. Severity of the case was more important than etiology; however, regardless of severity, microbiologically negative cases were not associated with reduced probability of pregnancy.
\end{abstract}

Received October 20, 2014.

Accepted February 11, 2015.

${ }^{1}$ Corresponding author: plruegg@wisc.edu
Key words: mastitis, dairy, fertility, animal reproduction

\section{INTRODUCTION}

Reproductive efficiency is one of the most important factors associated with dairy farm profitability and is negatively affected by diseases such as mastitis. The occurrence of mastitis has been associated with increased days to first AI (Barker et al., 1998; Schrick et al., 2001; Santos et al., 2004), increased services per conception (Schrick et al., 2001; Santos et al., 2004; Ahmadzadeh et al., 2009), increased days open (Schrick et al., 2001; Santos et al., 2004; Ahmadzadeh et al., 2009), increased incidence of pregnancy loss (Risco et al., 1999; Santos et al., 2004), and decreased pregnancies per AI at first AI (P/AI1; Santos et al., 2004).

Mastitis is a bacterial infection of the mammary gland that is recognized based on the inflammatory response to infection. Subclinical mastitis (SM) is defined as an IMI that results in an influx of inflammatory cells (somatic cells) and is usually detected based on increased SCC of milk (Ruegg and Erskine, 2014). Clinical mastitis (CM) is defined as an IMI that results in production of abnormal milk with or without abnormalities in the mammary gland or systemic symptoms (Pinzón-Sánchez and Ruegg, 2011; Ruegg and Erskine, 2014). The occurrence of both subclinical (Schrick et al., 2001; Lavon et al., 2011a,b; Hudson et al., 2012) and clinical (Moore et al., 1991; Santos et al., 2004; Hudson et al., 2012) mastitis has been associated with reduced reproductive performance. The occurrence of the mastitis event relative to insemination mediates the effect of mastitis on pregnancy outcomes (Barker et al., 1998; Santos et al., 2004). The most detrimental effects of mastitis on reproductive performance were observed when CM occurred near the time of AI (Hertl et al., 2010; Hudson et al., 2012) or during the interval between AI and first pregnancy diagnosis (Barker et al., 1998; Santos et al., 2004). The occurrence of SM during the same interval also negatively affects conception (Schrick et al., 2001; Lavon et al., 2011a; Hudson 
et al., 2012); however, the effects of repeated mastitis events occurring near the time of AI (either before or during AI) and between AI and the first pregnancy diagnosis have not been well described.

Mastitis is caused by a variety of pathogens, and the reported effect of specific pathogens on reproductive performance has been inconsistent. Several studies have reported similar reductions in reproductive performance for mastitis caused by gram-positive and gram-negative pathogens (Barker et al., 1998; Schrick et al., 2001; Santos et al., 2004). In contrast, Moore et al. (1991) and Hertl et al. (2010) both reported a greater reduction in reproductive outcomes when mastitis was caused by gram-negative compared with gram-positive organisms. Pathogen-specific differences in reproductive performance have been hypothesized to result from differences in the immune response to IMI caused by different pathogens (Schukken et al., 2011). However, severity of CM symptoms is associated with etiology (Oliveira and Ruegg, 2014) and no studies have evaluated the effect of severity of $\mathrm{CM}$ on reproductive outcomes. The objective of this study was to describe associations between the occurrence and severity of CM and SM occurring during a defined risk period with $\mathrm{P} /$ AI1 while accounting for etiology and previous mastitis events.

\section{MATERIALS AND METHODS}

\section{Herds and Cow Enrollment Criteria}

A total of 3,277 cows from 4 Wisconsin dairy herds were eligible to be enrolled in a prospective cohort study between May 2011 and November 2013. Eligibility criteria for farms included participation in monthly DHIA testing that included individual cow SCC data, use of DairyComp 305 for herd records, use of a con- sistent breeding program throughout the trial period, and administration of intramammary dry cow therapy to all quarters of all cows. Milking technicians were requested to use a complete milking routine that included forestripping for detection of clinical mastitis. All cows eligible to receive a first AI during the enrollment period on each farm were eligible for enrollment in the study, and each cow could be enrolled once. Cows not eligible for AI were excluded. Cows were also excluded if pregnancy status after AI was not available (due to culling or death) or if they did not have complete mastitis records (defined as the following data recorded for each case of CM: quarter affected, date identified, and severity, and for SM: individual cow SCC near AI). Cows were followed until the outcome of the first pregnancy diagnosis was ascertained.

Of a total of 4,378 lactating cows that were present on the 4 enrolled farms, 3,277 were eligible for first AI during the enrollment period (Table 1). Of eligible cows, 113 did not receive a first AI and were not enrolled (Table 1$)$. Cows $(n=889)$ were enrolled on farm A between May to November 2011; cows $(\mathrm{n}=981)$ were enrolled on farm B between March 2012 until February 2013; cows $(\mathrm{n}=735)$ were enrolled on farm C between May 2012 until July 2013; and cows $(\mathrm{n}=559)$ were enrolled on farm D between March to November 2013. Of the enrolled cows $(\mathrm{n}=3,164)$, severity scores were not recorded for 20 cows, leaving 3,144 cows with complete records for statistical analysis (Table 1).

All procedures were approved by the Animal Care and Use Committee for the College of Agricultural and Life Sciences of the University of Wisconsin-Madison.

\section{Data Collection}

During the data collection period (from calving to first pregnancy diagnosis), the occurrence of SM was

Table 1. Descriptive characteristics of enrolled cows $(\mathrm{n}=3,164)$ from 4 Wisconsin dairy herds

\begin{tabular}{|c|c|c|c|c|c|c|c|c|}
\hline Farm & $\begin{array}{l}\text { Milking cows } \\
\text { per herd (n) }\end{array}$ & $\begin{array}{l}\text { Cows eligible } \\
\text { for the study }\end{array}$ & $\begin{array}{l}\text { Cows enrolled } \\
\text { in the study }\end{array}$ & $\begin{array}{l}\text { Cows used } \\
\text { for analysis }\end{array}$ & $\begin{array}{c}\mathrm{P} / \mathrm{AI}^{4} \\
(\%)\end{array}$ & $\begin{array}{c}\text { Use of } \\
\operatorname{Synch}^{5}(\%)\end{array}$ & $\begin{array}{l}\text { Milk yield }^{6} \\
(\mathrm{~kg})\end{array}$ & $\begin{array}{c}\mathrm{SCC}^{7} \\
\text { (cells/mL) }\end{array}$ \\
\hline A & 1,429 & 913 & 889 & 888 & $39.0^{\mathrm{a}}$ & $93.9^{\mathrm{c}}$ & $46.1^{b}$ & $51,823^{\mathrm{b}}$ \\
\hline B & 1,382 & 1,017 & 981 & 965 & $44.7^{\mathrm{b}}$ & $87.6^{\mathrm{b}}$ & $46.0^{\mathrm{b}}$ & $47,492^{\mathrm{ab}}$ \\
\hline D & 750 & 586 & 559 & 557 & $38.6^{\mathrm{a}}$ & $57.6^{\mathrm{a}}$ & $43.0^{\mathrm{a}}$ & $72,639^{\mathrm{c}}$ \\
\hline Total & 4,378 & 3,277 & 3,164 & 3,144 & 42.9 & 86.7 & 46.1 & 51,788 \\
\hline
\end{tabular}

\footnotetext{
${ }^{\mathrm{a}-\mathrm{d}}$ Within a column among farms, means (ANOVA) or proportions (logistic regression) with different superscripts differ $(P<0.05)$.

${ }^{1}$ Cows eligible for AI at first service.

${ }^{2}$ Cows submitted for first service.

${ }^{3}$ Enrolled cows that had complete records of the severity of CM and used for statistical analysis.

${ }^{4}$ Pregnancies per artificial insemination at first AI (P/AI1).

${ }^{5}$ Percentage of cows submitted for first AI using a hormonal synchronization protocol.

${ }^{6}$ Milk yield from 3 d before to $32 \mathrm{~d}$ after first AI.

${ }^{7} \mathrm{SCC}$ from $3 \mathrm{~d}$ before to $32 \mathrm{~d}$ after first AI. Somatic cell count values were $\log _{10}$-transformed, then back-transformed to SCC per milliliter.
} 
determined using SCC values obtained from monthly DHIA data and CM events were detected and recorded by trained farm personnel. When CM was detected, trained milking technicians aseptically collected duplicate, quarter milk samples (during the same milking) that were frozen and transported to the laboratory by study personnel during weekly farm visits. Trained milking technicians assigned severity scores to each $\mathrm{CM}$ event and recorded cow identification, date of occurrence, treatment, and affected quarter(s). The severity score was defined as (1) mild CM, presence of abnormal milk without other symptoms; (2) moderate $\mathrm{CM}$, abnormal and local symptoms in the udder, or (3) severe CM, which includes systemic symptoms (PinzónSánchez and Ruegg, 2011; Ruegg, 2012; Oliveira et al., 2013). The SCC and milk yield from the DHIA test date closest to first AI were used to calculate geometric mean SCC and average milk yield for enrolled cows on each farm (Table 1).

\section{Microbiological Analysis of Milk Samples}

Microbiological analysis was performed at the University of Wisconsin Milk Quality laboratory according to National Mastitis Council (1999) guidelines. After arrival in the laboratory, milk samples were thawed at room temperature, and $100 \mu \mathrm{L}$ of milk from each duplicate sample was inoculated onto each half of an agar plate containing trypticase soy agar with $5 \%$ sheep blood. An additional, $10 \mu \mathrm{L}$ of milk was inoculated onto 1 quarter of a MacConkey agar plate. Plates were incubated at $37^{\circ} \mathrm{C}$ for 24 to $48 \mathrm{~h}$. Quarter milk samples were pooled and $100 \mu \mathrm{L}$ was inoculated in mycoplasma media broth; $72 \mathrm{~h}$ later $10 \mu \mathrm{L}$ of this suspension was plated onto 1 quarter of mycoplasma agar plate (Media Laboratory, School of Veterinary Medicine, University of California, Davis). Broth and agar were incubated in $6 \% \mathrm{CO}_{2}$ at $37^{\circ} \mathrm{C}$ for 3 and $14 \mathrm{~d}$, respectively. Mycoplasma agar plates were observed for growth every $2 \mathrm{~d}$ after inoculation for $21 \mathrm{~d}$. Microbiological diagnosis of mycoplasma was only performed for farm A, B, and D because farm $\mathrm{C}$ had no history of mycoplasma infections and was considered free of this disease.

Isolates that grew on MacConkey agar were inoculated on triple sugar iron slants, motility, indole and ornithine, and sodium citrate slants. Catalase tests were performed to differentiate Staphylococcus and Streptococcus. Mannitol and tube coagulase reactions were performed for catalase positive colonies. Christie, Atkins, Munch-Petersen (CAMP), esculin, and bile esculin reactions were performed for catalase-negative colonies. Gram staining characteristics and colony morphology were observed to arrive at a final microbiological diagnosis.
Microbiological diagnosis was defined at the quarter level. An IMI was defined as the isolation of $100 \mathrm{cfu} /$ $\mathrm{mL}$ of identical colonies. However, for Staphylococcus aureus, an IMI was defined as the isolation of at least $10 \mathrm{cfu} / \mathrm{mL}$. Mixed infection was defined as at least 3 colonies of each of 2 different types of bacteria found in the same milk sample. Milk samples were considered contaminated when 3 or more different colony types were isolated from the same sample. For analysis, results of quarter milk samples with nonsignificant growth $(<100 \mathrm{cfu} / \mathrm{mL})$ were combined with no growth. Criteria used to define etiology of quarter cases based on microbiological results from duplicate milk samples were based on Pinzón-Sánchez and Ruegg (2011). Etiologies were defined as follows: (1) results were identical from both duplicate milk samples; (2) no bacteria were recovered from 1 sample but pathogen was recovered from the other sample; (3) 1 sample was contaminated and pathogen was recovered from the other sample; (4) 1 sample was contaminated and no bacteria were recovered from the other sample; or (5) 1 sample was missing but pathogen or no bacteria was recovered from the duplicate. Etiologies of IMI in multiple quarters were defined as follows: (1) the same pathogen isolated from all affected quarters; (2) no growth when no bacteria were isolated from all affected quarters; (3) contaminated when all quarter samples were contaminated; and (4) excluded when one of the milk quarter samples was not available for culturing or when the bacteria cultured from quarters affected were not the same.

\section{Definitions}

Cows were categorized into 6 mastitis risk groups based on occurrence of SM and CM during or before the defined breeding risk period (BRP, Table 2). Based on previous research (Barker et al., 1998; Santos et al., 2004; Hudson et al., 2012), the BRP was defined as the period $3 \mathrm{~d}$ before to $32 \mathrm{~d}$ after first AI. Cases of CM that occurred more than $14 \mathrm{~d}$ after a previous case were considered new cases. To be consistent with previous work, SM was defined when monthly DHIA SCC exceeded 150,000 cells per $\mathrm{mL}$ (Lavon et al., 2011a). The occurrence of CM or SM 40 d before the BRP (or date of $\mathrm{CM}$ occurring during the breeding risk period was also used to assign cows to mastitis risk groups (Table 2 ). The mastitis risk groups included (1) healthy: no SM or CM during or before the BRP; (2) mastitis before BRP: no occurrence of CM or SM during the BRP but occurrence of $\mathrm{CM}$ or $\mathrm{SM}$ events previous to the BRP; (3) SM during BRP: occurrence of 1 or $2 \mathrm{SM}$ events during the BRP with no previous history of SM or CM; (4) chronic SM: occurrence of 1 or $2 \mathrm{SM}$ events during the BRP and occurrence of $\mathrm{CM}$ or SM events 
Table 2. Criteria used to define mastitis risk groups based on occurrence of clinical mastitis (CM) or subclinical mastitis (SM) during or before the breeding risk period (BRP; 3 d before to $32 \mathrm{~d}$ after first $\mathrm{AI}$ ) for cows $(\mathrm{n}=3,144)$ on 4 Wisconsin dairy herds

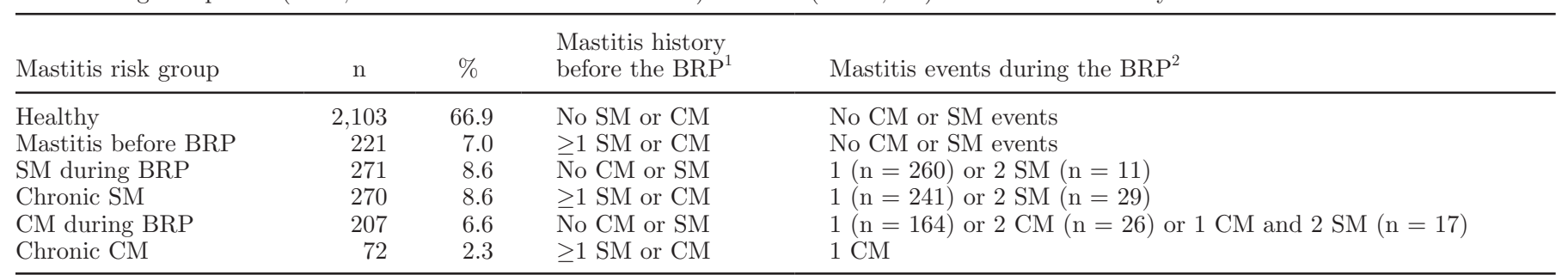

${ }^{1}$ Occurrence of CM or SM (SCC $\geq 150,000$ cells $/ \mathrm{mL}$ ) in 40 d-period before the BRP or before date of CM occurring during the BRP.

${ }^{2}$ Cases of $\mathrm{CM}$ that occurred more than $14 \mathrm{~d}$ from previous cases were considered new cases. Somatic cell count tests occurred at least $30 \mathrm{~d}$ apart from previous SCC test.

previous to the BRP; (5) CM during BRP: occurrence of a 1 or $2 \mathrm{CM}$ event during the BRP with no previous history of SM or CM; or (6) chronic CM: occurrence of a single $\mathrm{CM}$ event during BRP with occurrence of SM or CM previous to BRP (Table 2).

\section{Reproductive Management}

Cows were submitted for first AI using hormonal synchronization protocols as part of the routine reproductive management programs for each farm. For farm A, most cows received their first AI between 75 and 85 DIM. For farm B, most cows received their first AI between 57 and 100 DIM. For farm C, most cows received their first AI between 76 and 84 DIM. For farm D, most cows received their first AI between 53 and 86 DIM. Ovulation was synchronized using GnRH $(100 \mu \mathrm{g}$ of gonadolerin diacetate tetrahydrate) and $\mathrm{PGF}_{2 \alpha}(25 \mathrm{mg}$ of dinoprost tromethamine). Depending on the farm, timed AI was performed using 1 of 3 presynchronization schemes: (1) Presynch-Ovsynch $\left[2\right.$ injections of $\mathrm{PGF}_{2 \alpha}$ administered $14 \mathrm{~d}$ apart before starting an Ovsynch protocol 12 to 14 d later (Pursley et al., 1995; Moreira et al., 2001)]; (2) double-Ovsynch [DO; GnRH injection, $\mathrm{PGF}_{2 \alpha} 7 \mathrm{~d}$ later, and GnRH 3 d later, followed by GnRH 7 d later, $\mathrm{PGF}_{2 \alpha} 7$ d later, GnRH 56 h later and AI 16 h later (Souza et al., 2008)]; or (3) a GGPG protocol [GnRH injection $7 \mathrm{~d}$ before an Ovsynch protocol (Giordano et al., 2012)]. Cows detected in estrus after the second $\mathrm{PGF}_{2 \alpha}$ injection of the Presynch-Ovsynch protocol were inseminated; therefore, they did not receive the first GnRH injection of the Ovsynch protocol. For analysis, breeding protocols were categorized as (1) timed AI after a synchronization protocol (PresynchOvsynch, DO, or GGPG) or (2) AI after estrus.

Pregnancy examinations were performed on all farms using transrectal ultrasonography 27 to $32 \mathrm{~d}$ after AI. A positive pregnancy diagnosis was based on visualization of a corpus luteum on the ovary ipsilateral to the uterine horn containing an embryo with a heartbeat. Pregnancies per first AI was calculated by dividing the number of cows diagnosed pregnant by the total number of cows inseminated.

\section{Statistical Analyses}

Statistical analyses were performed using SAS version 9.3 (SAS Institute, 2011). Cow was considered the experimental unit. The effect of selected risk factors (explanatory variables) on P/AI1 27 to $32 \mathrm{~d}$ after AI (response variable) was determined using logistic regression. Categorical variables included severity of CM (Pinzón-Sánchez and Ruegg, 2011), categorized etiology of CM (gram-negative, gram-positive, or no growth), and the defined mastitis risk groups: (1) SM during BRP, (2) CM during BRP, (3) chronic SM, (4) chronic CM, (5) mastitis before BRP, and (6) healthy (Table 2 ). Etiology and severity of CM cases were combined into 1 variable with 7 categories: (1) healthy, (2) no growth and mild (NGM), (3) no growth and moderatesevere (NGMS), (4) gram-positive and mild (GPM), (5) gram-positive and moderate-severe (GPMS), (6) gram-negative and mild (GNM), (7) gram-negative and moderate-severe cases (GNMS). Parity $(1,2$, and $\geq 3$ ), season of AI (fall, winter, spring, and summer), breeding protocol, and daily milk production at time of AI ( $\mathrm{kg} / \mathrm{cow}$ per day) were evaluated as potential confounding variables.

Summary statistics were compared among farms. For categorical variables, differences in P/AI1 based on use of a synchronization protocol were performed using PROC LOGISTIC. For continuous variables, differences in milk yield (kg/cow per day) and SCC (cells/ $\mathrm{mL}$ ) during the BRP were performed using ANOVA tests with PROC GLM.

To determine differences in explanatory variables among farms, univariate analyses were performed using PROC FREQ. Comparisons among farms were 
performed using chi-squared analyses or Fisher exact test (when expected value was $<5$ ).

Univariate relationships between $\mathrm{P} / \mathrm{AI} 1$ and risk factors were assessed using Cochran-Mantel-Haenszel analysis with PROC FREQ. After adjusting for the effect of farm, differences in probability of P/AI1 among levels of selected risk factors were assessed by logistic regression using PROC LOGISTIC. Parity was initially categorized using 3 levels $(1,2$, and $\geq 3)$, but estimates showed that $\mathrm{P} / \mathrm{AI} 1$ did not differ for parity 2 and $\geq 3$ cows, so further analysis used only 2 levels (primiparous and multiparous). Season of AI was initially categorized using 3 levels (winter-spring, fall, summer); however, $\mathrm{P}$ / AI1 for cows bred during fall and winter-spring did not differ, so further analysis used 2 levels (warm season, cool season). Likewise, severity was initially analyzed using 3 categories (mild, moderate, severe), but because few cases were severe, multivariate modeling was performed using 2 categories (mild, moderate-severe). Etiology and severity of CM were initially categorized using 7 levels (healthy, NGM, NGMS, GPM, GPMS, GNM, and GNMS), but estimates showed that P/AI1 did not differ for GPM and GNM, and GPMS and GNMS; thus, further analysis used 5 levels (healthy, NGM, NGMS, gram-positive and gram-negative and mild, and gram-positive and gram-negative and moderate-severe).Variables and biologically plausible interactions with a $P$-value $<0.25$ in a univariate analysis were offered into multivariate models.

Multivariate analyses were performed using PROC GLIMMIX with farm included as a random effect. Potential confounding variables included parity and season of AI and were included in all multivariate logistic models. The outcome variable was the probability of $\mathrm{P} /$ AI1. Milk yield during the BRP ( $\mathrm{kg} / \mathrm{cow}$ per day) was not associated with $\mathrm{P} / \mathrm{AI} 1$ at first $\mathrm{AI}(P=0.366)$ and was not eligible for entry in multivariate models.

Four separate logistic regression models were used to assess the associations of mastitis and P/AI1. Model 1 used data from 3,144 cows to assess the association between mastitis risk group and P/AI1 after first AI. The hypothesis was that probability of pregnancy differed among mastitis risk groups. Explanatory variables included in the final model included parity, season of AI, method of AI, mastitis risk group, and interactions between parity and season of AI.

Model 2 used a subset of data $(n=2,382$ cows $)$ to assess the association of severity of CM (mild, moderate-severe cases) during the BRP with $\mathrm{P} / \mathrm{AI} 1$. Cows experiencing only SM during the BRP were excluded from this analysis and the comparison group for this analysis was cows that remained healthy before and during the BRP. The hypothesis was that probability of pregnancy was associated with severity of CM. Ex- planatory variables included in the final model included parity, season of AI, method of AI, severity of CM, and interaction between parity and season of AI. Because no cases of mild CM were recorded for farm D, analysis was performed with and without inclusion of data from that farm. Estimates and model fit were not meaningfully influenced by the exclusion of farm $\mathrm{D}$, so results of the model that included all 4 farms are presented.

Model 3 used a subset of data $(\mathrm{n}=2,321$ cows) to assess the association of etiology of $\mathrm{CM}$ with $\mathrm{P}$ / AI1. Only data from cows that had complete microbiological results were included in this analysis. Cows experiencing only SM during the BRP were excluded and the comparison group for this analysis was cows that remained healthy before and during the BRP. The hypothesis was that probability of pregnancy after first AI was associated with etiology of CM. Explanatory variables included in the final logistic regression model 3 included parity, season of AI, method of AI, etiology of CM, and interaction between parity and season of AI.

Model 4 used a subset of data $(n=2,321$ cows $)$ to assess the association between etiology and severity of $\mathrm{CM}$ with P/AI1. Similar to models 2 and 3, cows that had complete microbiological results and severity of $\mathrm{CM}$ were included in this analysis. Cows experiencing only SM during the BRP were excluded, and the comparison group for this analysis was cows that remained healthy before and during the BRP. The hypothesis was that probability of pregnancy after first AI was associated with etiology and severity of CM. Explanatory variables included in final logistic regression model 4 included parity, season of AI, method of AI, etiology and severity of $\mathrm{CM}$, and interaction between parity and season of AI. Similar to model 3, because no cases of mild CM were recorded for farm D, analysis was performed with and without inclusion of data from that farm. Because the estimates and model fit were not meaningfully influenced by the exclusion of farm $\mathrm{D}$, results of the model that included all 4 farms are presented.

For all models, goodness of fit was assessed using the -2 Res Log Pseudo-Likelihood of PROC GLIMMIX.

\section{RESULTS}

\section{Herd Characteristics}

Enrolled farms contained between 750 to 1,429 lactating cows. The average milk yield was $46.1 \mathrm{~kg} / \mathrm{cow}$ per day and ranged from 43.0 to $48.6 \mathrm{~kg} / \mathrm{cow}$ per day. The geometric mean SCC during the BRP was 51,788 cells/ $\mathrm{mL}$ (ranging from 44,723 to 72,639 cells/mL, Table 1 ). Overall, $86.7 \%$ of inseminations were performed using 
estrous or ovulation synchronization protocols (ranging from 57.6 to $99.5 \%$ ), and the average P/AI1 at first AI was $42.9 \%$ (ranging from 38.6 to $48.7 \%$ ).

Most descriptive characteristics varied among farms $(P<0.003)$. The overall distribution of parities was $44.1 \%$ (lactation 1), $29.4 \%$ (lactation 2), and $26.5 \%$ (lactation $\geq 3$ ). Cows were inseminated during winter $(10.1 \%)$, spring $(20.8 \%)$, summer $(35.9 \%)$, or fall (33.1\%), but because of differences among farm enrollment periods, no winter inseminations were enrolled on 2 farms. Breeding protocols varied among farms and were performed using AI after detection of estrus (13.1\%), and TAI after Presynch-Ovsynch (57.6\%), GGPG $(3.4 \%)$, and DO (25.9\%).

Based on the definition of SM, approximately $21.6 \%$ of cows had SM during the BRP and the proportion of cows with SM varied among farms, ranging from $17.0 \%$ (farm C) to $30.8 \%$ (farm D; $P<0.001$ ). During the BRP, $8.9 \%$ of cows experienced $\mathrm{CM}$, and the proportion of cows with $\mathrm{CM}$ varied among farms $(P<$ 0.001 ), ranging from $2.7 \%$ (farm D) to $17.1 \%$ (farm B). Of cows that experienced CM during the BRP ( $\mathrm{n}=$ 279 ), the distribution of severity scores was $61.3 \%$ mild, $26.9 \%$ moderate, and $11.8 \%$ severe, and the proportion of cows in each of these severity scores varied $(P$ $<0.001$ ) among farms. Of CM cases, $88.2 \%$ occurred in single mammary gland quarter and $11.8 \%$ included multiple quarters. The categorized etiology of CM cases was gram-negative $(24.3 \%)$, gram-positive $(33.5 \%)$, and no growth $(42.2 \%)$ and varied $(P=0.003)$ among farms (Table 3). Within the BRP, gram-negative bacteria caused $17.0 \%$ (farm B) to $53.8 \%$ (farm D) of the CM events, whereas gram-positive bacteria caused $16.0 \%$ (farm A) to $40.0 \%$ (farm B and C) of the CM events. No bacteria were recovered from milk samples of cases of CM obtained from 23.1\% (farm D) to $52.0 \%$ (farm A). For gram-negative cases, the distribution of severities was $35.8 \%$ (mild), $37.7 \%$ (moderate), and $26.4 \%$ (severe). For gram-positive cases, the distribution of severities was $54.8 \%$ (mild), $35.6 \%$ (moderate), and $9.6 \%$ (severe). For no growth cases, the distribution of severities was $81.5 \%$ (mild), $12.0 \%$ (moderate), and $6.5 \%$ (severe). Etiology and severity of $\mathrm{CM}$ varied $(P$ $=0.009$ ) among farms, and the overall distribution by category was $34.4 \%$ (NGM), 7.8\% (NGMS), $18.3 \%$ (GPM), $15.1 \%$ (GPMS), $8.7 \%$ (GNM), and $15.6 \%$ (GNMS).

Mastitis risk group varied among farms, and the distribution of cows by risk group was $66.9 \%$ (healthy), $7.0 \%$ (mastitis before BRP), $8.6 \%$ (SM during BRP), $8.6 \%$ (chronic SM), $6.6 \%$ (CM during BRP), and $2.3 \%$ (chronic CM; $P<0.001$ ).

\section{Microbiological Results}

The etiologies of CM cases occurring during the BRP $(\mathrm{n}=279)$ were Staphylococcus aureus $(\mathrm{n}=6,2.5 \%$, most isolates were recovered from farm B), CNS ( $\mathrm{n}=3$, $1.3 \%)$, Streptococcus agalactiae $(\mathrm{n}=1,0.4 \%)$, environmental streptococci $(\mathrm{n}=43,18.1 \%)$, Enterococcus spp. ( $\mathrm{n}=9,3.8 \%)$, Lactococcus $\mathrm{spp} .(\mathrm{n}=7,2.9 \%)$, other gram-positive ( $\mathrm{n}=5,2.1 \%)$, Escherichia coli $(\mathrm{n}=26$, $10.9 \%)$, Klebsiella spp. $(\mathrm{n}=11,4.6 \%)$, Enterobacter spp. $(\mathrm{n}=4,1.7 \%)$, other gram-negative $(\mathrm{n}=11,4.6 \%)$, mixed cultures $(\mathrm{n}=15,6.3 \%)$, yeast $(\mathrm{n}=5,2.1 \%)$, and no growth $(\mathrm{n}=92,38.7 \%)$. Missing and contaminated samples represented $6.8 \%(\mathrm{n}=19)$ and $5.0 \%(\mathrm{n}=14)$, respectively, of the total cases. Data from 8 cows that experienced multiple quarter infections were excluded from analysis.

\section{Univariate Relationships Between P/Al1 and Selected Risk Factors}

The overall probability of $\mathrm{P} / \mathrm{AI} 1$ was greater $(P$ $<0.001)$ for primiparous than multiparous cows and was less $(P=0.002)$ for cows inseminated in summer compared with cows inseminated during other seasons (Table 3). Overall, cows inseminated after a detected estrus or inseminated using TAI after Presynch-Ovsynch had a decreased $(P=0.003)$ probability of pregnancy compared with cows inseminated after GGPG or DO protocols (Table 3 ).

The occurrence of both SM and CM during the BRP was associated with reduced P/AI1 compared with cows without mastitis (Table 3). As compared with healthy cows, probabilities of P/AI1 were decreased $(P$ $<0.001$ ) for cows that experienced CM of any severity, but no difference in P/AI1 was observed between cows that experienced mild $\mathrm{CM}$ and cows that experienced moderate or severe CM (Table 3). Pregnancies/AI1 was associated with mastitis risk group and was least for cows categorized as having chronic CM and greatest for healthy cows and cows categorized as having mastitis before the BRP (Table 3). Pregnancies/AI1 were associated with etiology of CM and was least for cows that experienced CM caused by gram-positive or gram-negative bacteria compared with healthy cows or cows that experienced CM for which no bacteria were recovered (Table 3). Pregnancies/AI1 was associated with etiology and severity of CM and was least for cows that experienced moderate-severe CM that was caused by either gram-positive or gram-negative bacteria (Table 3). 


\section{Results of the Multivariate Model 1 for Association of Mastitis Risk Group and P/Al1}

The final multivariate logistic model for the association of mastitis risk group and P/AI1 included parity, season of AI, method of AI, mastitis risk groups, and interactions between parity and season of AI (Table 4). Primiparous cows had a greater probability of pregnancy compared with multiparous cows $(P<0.001)$. The probability of pregnancy was less $(P<0.001)$ for cows inseminated during the warm season as compared with cows inseminated during the cool season. Cows inseminated receiving TAI (following a synchronized estrous or ovulation program) were more likely to become pregnant compared with cows inseminated after a detected estrus (Table 4). A significant interaction was found between parity and season of AI (Table 4). The odds of pregnancy were least for multiparous cows bred during the warm season compared with multiparous cows bred during cool season or primiparous cows bred in either season (Table 4).

As compared with healthy cows, the probability of pregnancy was decreased for cows that were categorized as having SM during the $\mathrm{BRP}(\mathrm{OR}=0.75 ; P=$ 0.031), cows that experienced CM during the BRP (OR $=0.67 ; P=0.012)$, and cows that were categorized as having chronic $\mathrm{CM}(\mathrm{OR}=0.56, P=0.029)$. The probability of pregnancy was not associated with the occurrence of mastitis before the BRP or the categorization of a cow as having chronic SM. The value for -2 Res Log Pseudo-Likelihood goodness of fit for model 1 was 13,472 .

\section{Results of Multivariate Model 2 for Association of P/Al1 with Severity of CM}

Similar to model 1, the final multivariate logistic model for association of severity of CM occurring during the BRP and P/AI1 at first AI included parity, season of AI, method of AI, severity of CM, and interaction between parity and season of AI (Table 5). Estimates for the effect of parity, season, and method of AI were similar to results of model 1 . After including interaction terms and controlling for parity $(P<0.001)$, season of AI $(P<0.001)$, method of AI $(P=0.089)$, severity of $\mathrm{CM}$ during the BRP was associated with the probability of pregnancy after first AI $(P=0.004$; Table 5$)$.

Compared with healthy cows, the odds of pregnancy at first AI were 0.71 and 0.54 for cows categorized as having mild or moderate-severe mastitis during the BRP, respectively, but the 95\% CI for those categories overlapped (Table 5). The value for -2 Res Log Pseudo-Likelihood goodness of fit for this model was 10,201.

\section{Results of Multivariate Model 3 for Association of Etiology of CM and P/Al1}

Similar to models 1 and 2 , the final multivariate logistic model for association of etiology of $\mathrm{CM}$ during the BRP and P/AI1 included parity, season of AI, method of AI, etiology of CM and interaction between parity and season of AI (Table 6). Estimates for the effect of parity, season, and method of AI were similar to results of models 1 and 2. After including interaction terms and controlling for parity $(P<0.001)$, season of AI $(P<0.001)$, and method of AI $(P=0.058)$, etiology of $\mathrm{CM}$ during the BRP was associated with $(P=0.028)$ the probability of pregnancy after first AI (Table 6).

Compared with healthy cows, the odds of pregnancy at first AI were 0.59 and 0.47 for cows experiencing mastitis caused by gram-positive and gram-negative CM during the BRP, respectively, but the $95 \%$ CI for those categories overlapped (Table 6). Compared with healthy cows, the probability of pregnancy was not decreased for cows that experienced CM during the BRP from which the milk sample resulted in no microbial growth (Table 6). The value for -2 Res Log PseudoLikelihood goodness of fit for this model was 9,933 .

\section{Results of Multivariate Model 4 for Association of Etiology and Severity of CM and P/Al1}

Similar to models 1 to 3 , the final multivariate logistic model for association of etiology and severity of $\mathrm{CM}$ during the BRP and P/AI1 included parity, season of AI, method of AI, etiology and severity of CM, and interaction between parity and season of AI (Table 7). Estimates for the effect of parity, season, and method of AI were similar to results of models 1 to 3. After including interaction terms and controlling for parity $(P$ $<0.001)$, season of AI $(P=0.002)$, and method of AI $(P=0.054)$, the combined category of etiology-severity of CM during the BRP was associated with the probability of pregnancy after first AI $(P=0.032$; Table 7). When compared with healthy cows, the odd of $\mathrm{P} /$ AI1 was 0.41 for cows experiencing moderate-severe mastitis caused by gram-positive and gram-negative pathogens (Table 7). The odds of pregnancy were not reduced for cows that experienced clinical mastitis that was culture negative nor microbiologically positive CM that presented with mild symptoms. The value for the -2 Res Log Pseudo-Likelihood goodness of fit for this model was 9,933 .

\section{DISCUSSION}

Milk yield and management practices of enrolled farms were typical of large Wisconsin farms and were 


\begin{tabular}{|c|c|c|c|c|c|c|c|c|c|c|c|c|c|}
\hline \multirow[b]{3}{*}{ Risk factors } & \multicolumn{8}{|c|}{$\mathrm{P} / \mathrm{AI} 1$} & \multirow[b]{3}{*}{$P$-value ${ }^{1}$} & & & \multirow[b]{3}{*}{$\mathrm{LSM}^{2}$} & \multirow[b]{3}{*}{$P$-value } \\
\hline & \multicolumn{2}{|c|}{ Farm A } & \multicolumn{2}{|c|}{ Farm B } & \multicolumn{2}{|c|}{ Farm C } & \multicolumn{2}{|c|}{ Farm D } & & \multicolumn{2}{|c|}{ Overall P/AI1 } & & \\
\hline & $\mathrm{n}$ & $\%$ & $\mathrm{n}$ & $\%$ & $\mathrm{n}$ & $\%$ & $\mathrm{n}$ & $\%$ & & $\mathrm{n}$ & $\%$ & & \\
\hline Parity & & & & & & & & & $<0.001$ & & & & $<0.001$ \\
\hline 1 & 365 & 45.7 & 489 & 50.1 & 292 & 53.1 & 241 & 46.9 & & 1387 & 49.0 & $0.49^{\mathrm{a}}$ & \\
\hline 2 & 271 & 33.2 & 318 & 38.4 & 197 & 46.7 & 139 & 31.6 & & 925 & 37.6 & $0.37^{\mathrm{b}}$ & \\
\hline$\geq 3$ & 252 & 35.3 & 158 & 39.2 & 245 & 45.3 & 177 & 32.8 & & 832 & 38.5 & $0.38^{\mathrm{b}}$ & \\
\hline Season of $\mathrm{AI}^{3}$ & & & & & & & & & $<0.001$ & & & & 0.002 \\
\hline Fall & 339 & 49.0 & 345 & 44.6 & 181 & 43.6 & 177 & 34.5 & & 1042 & 44.1 & $0.44^{\mathrm{b}}$ & \\
\hline Winter & 0 & - & 141 & 45.4 & 176 & 50.6 & 0 & - & & 317 & 48.3 & $0.45^{\mathrm{b}}$ & \\
\hline Spring & 114 & 37.2 & 173 & 47.4 & 197 & 55.8 & 171 & 43.3 & & 655 & 47.2 & $0.47^{\mathrm{b}}$ & \\
\hline Summer & 435 & 31.5 & 306 & 42.2 & 180 & 44.4 & 209 & 38.3 & & 1130 & 37.7 & $0.38^{\mathrm{a}}$ & \\
\hline Breeding protocol $^{4}$ & 100 & (.0.0 & 000 & T2.2 & 100 & T1. & 200 & 00.0 & 0.003 & 1100 & S1. & 0.00 & 0.003 \\
\hline AI after detection of estrus & 54 & 40.7 & 120 & 37.5 & 3 & 0.0 & 236 & 37.3 & & 413 & 37.5 & $0.36^{\mathrm{a}}$ & \\
\hline TAI after Presynch-Ovsynch & 636 & 35.5 & 845 & 45.4 & 9 & 44.4 & 321 & 39.6 & & 1,811 & 40.9 & $0.39^{\mathrm{a}}$ & \\
\hline TAI after GGPG & 0 & - & 0 & - & 107 & 47.7 & 0 & - & & 107 & 47.7 & $0.52^{\mathrm{b}}$ & \\
\hline TAI after Double-Ovsynch & 198 & 49.5 & 0 & - & 615 & 49.3 & 0 & - & & 813 & 49.3 & $0.53^{\mathrm{b}}$ & \\
\hline Subclinical mastitis $^{5}$ & & & & & & & & & $<0.001$ & & & & $<0.001$ \\
\hline Yes & 188 & 31.9 & 188 & 35.1 & 125 & 47.2 & 171 & 35.1 & & 672 & 36.5 & $0.37^{\mathrm{a}}$ & \\
\hline No & 699 & 40.9 & 749 & 46.9 & 609 & 49.1 & 385 & 40.0 & & 2442 & 44.6 & $0.44^{\mathrm{b}}$ & \\
\hline Clinical mastitis ${ }^{6}$ & & & & & & & & & $<0.001$ & & & & $<0.001$ \\
\hline Yes & 66 & 18.2 & 165 & 37.0 & 33 & 45.4 & 15 & 20.0 & & 279 & 32.6 & $0.31^{\mathrm{a}}$ & \\
\hline No & 822 & 40.6 & 800 & 46.0 & 701 & 48.9 & 542 & 39.1 & & 2865 & 43.9 & $0.44^{\mathrm{b}}$ & \\
\hline Severity of $\mathrm{CM}^{7}$ & & & & & & & & & $<0.001$ & & & & $<0.001$ \\
\hline Healthy & 606 & 42.4 & 622 & 47.9 & 539 & 48.2 & 336 & 38.4 & & 2,103 & 44.9 & $0.44^{\mathrm{a}}$ & \\
\hline Mild & 54 & 22.2 & 101 & 38.6 & 16 & 50.0 & 0 & - & & 171 & 34.5 & $0.33^{\mathrm{b}}$ & \\
\hline Moderate-severe & 12 & 0.0 & 64 & 34.4 & 17 & 41.2 & 15 & 20.0 & & 108 & 29.6 & $0.28^{\mathrm{b}}$ & \\
\hline Mastitis risk group ${ }^{8}$ & & & - & 1.1. & & & & & $<0.001$ & & & & $<0.001$ \\
\hline Healthy & 606 & 42.4 & 622 & 47.9 & 539 & 48.2 & 336 & 38.4 & & 2,103 & 44.9 & $0.45^{\mathrm{ac}}$ & \\
\hline Mastitis before BRP & 60 & 36.7 & 59 & 47.5 & 54 & 57.4 & 48 & 52.1 & & 221 & 48.0 & $0.48^{\mathrm{ac}}$ & \\
\hline SM during BRP & 69 & 31.9 & 60 & 33.3 & 53 & 52.8 & 89 & 31.5 & & 271 & 36.2 & $0.37^{\mathrm{b}}$ & \\
\hline Chronic SM & 87 & 37.9 & 59 & 37.3 & 55 & 43.6 & 69 & 43.5 & & 270 & 40.4 & $0.41^{\mathrm{bc}}$ & \\
\hline $\mathrm{CM}$ during $\mathrm{BRP}$ & 47 & 14.9 & 124 & 39.5 & 26 & 42.3 & 10 & 30.0 & & 207 & 33.8 & $0.33^{\mathrm{b}}$ & \\
\hline Chronic CM & 19 & 26.3 & 41 & 29.3 & 7 & 57.1 & 5 & 0.0 & & 72 & 29.2 & $0.28^{\mathrm{b}}$ & \\
\hline Etiology of CM & & & & & & & & & 0.002 & & & & 0.007 \\
\hline Healthy & 606 & 42.4 & 622 & 47.9 & 539 & 48.2 & 336 & 38.4 & & 2103 & 44.9 & $0.43^{\mathrm{a}}$ & \\
\hline No growth & 26 & 26.9 & 58 & 46.5 & 5 & 60.0 & 3 & 33.3 & & 92 & 41.3 & $0.40^{\mathrm{ab}}$ & \\
\hline Gram-positive & 8 & 25.0 & 54 & 33.3 & 8 & 50.0 & 3 & 0.0 & & 73 & 32.9 & $0.30^{\mathrm{b}}$ & \\
\hline Gram-negative & 16 & 0.0 & 23 & 34.8 & 7 & 57.1 & 7 & 14.3 & & 53 & 24.5 & $0.24^{\mathrm{b}}$ & \\
\hline Etiology and severity of $\mathrm{CM}^{9}$ & & & & & & & & & 0.013 & & & & 0.018 \\
\hline Healthy & 606 & 42.4 & 622 & 47.9 & 539 & 48.2 & 336 & 38.4 & & 2,103 & 44.9 & $0.44^{\mathrm{ad}}$ & \\
\hline NGM & 24 & 29.2 & 47 & 44.7 & 4 & 50.0 & 0 & - & & 75 & 40.0 & $0.38^{\mathrm{cd}}$ & \\
\hline NGMS & 2 & 0.0 & 11 & 54.5 & 1 & 100.0 & 3 & 33.3 & & 17 & 47.1 & $0.45^{\mathrm{cd}}$ & \\
\hline GPM & 8 & 25.0 & 26 & 38.5 & 6 & 50.0 & 0 & - & & 40 & 37.5 & $0.35^{\mathrm{c}}$ & \\
\hline GPMS & 0 & - & 28 & 28.6 & 2 & 50.0 & 3 & 0.0 & & 33 & 27.3 & $0.25^{\mathrm{bc}}$ & \\
\hline
\end{tabular}


reasonably representative of large dairy farms in this region (Caraviello et al., 2006). Although the SCC of enrolled cows was less than the overall average of Wisconsin dairy herds $(207,000$ cells per mL, Norman and Walton, 2013), only the SCC of the test-day closest to the first AI was used and SCC is often less during this period because cows have had a shorter period to develop chronic IMI (Dohoo and Meek, 1982). Use of a synchronization program was a farm enrollment requirement for participation in the study, and the proportion of cows submitted for first AI using hormonal synchronization protocols was similar to that reported by Caraviello et al. (2006). Likewise, the average pregnancies per AI (42.9\%) was similar to previous studies of farms that used similar reproductive management strategies (Carvalho et al., 2014; Fricke et al., 2014). Although just 4 herds were enrolled, a large number of cows were included and the farms used typical management practices. Thus, it is likely that results of this study can be extrapolated to herds in similar climates that are managed using similar breeding programs.

Compared with previous studies (Barker et al., 1998; Schrick et al., 2001; Santos et al., 2004), the current study used a greater variety of breeding protocols and cows were exposed to a greater diversity of mastitis pathogens. When multiple commercial dairy farms are enrolled in mastitis studies, it is challenging to ensure that a standardized case definition for CM is used and that detection intensity for CM does not vary among farms. Other studies have not always included a consistent definition of CM nor always defined detection methods. Some studies provided no clear definition of CM (Barker et al., 1998; Schrick et al., 2001; Hudson et al., 2012), whereas others have defined CM based on the presence of abnormal milk or signs of inflammation in the udder (Chebel et al., 2004; Santos et al., 2004; Ahmadzadeh et al., 2009). Other studies have defined $\mathrm{CM}$ based on visible changes in the udder, changes in milk consistency, or electrical conductivity of milk (Hertl et al., 2010). In the current study, a standardized severity scoring system was prospectively defined, and the overall distribution of severity of cases was similar to other studies (Pinzón-Sánchez and Ruegg, 2011; Oliveira et al., 2013). To ensure compliance with study protocols, each farm was visited at least weekly by the same researcher. Laboratory procedures remained consistent and microbiological analysis was performed by the same technician. However, based on proximity to the university, farm size, and willingness to participate, farm D was allowed to enroll even though the milking technicians did not consistently forestrip cows. On this farm, no mild cases of CM were enrolled and it is likely that some of these cases were misclassified as SM. Because the detection of mild CM was insufficient, the 
Table 4. Final logistic regression model for association of mastitis risk group and pregnancies per AI at first AI (P/AI1) after AI for 3,144 cows in 4 Wisconsin dairy herds ${ }^{1}$

\begin{tabular}{|c|c|c|c|c|c|}
\hline Variable & $\mathrm{n}$ & $\mathrm{LSM}^{2}$ & SEM & OR $(95 \% \mathrm{CI})$ & $P$-value \\
\hline Intercept & & 0.04 & 0.22 & & \\
\hline \multicolumn{5}{|l|}{ Parity } & \multirow[t]{3}{*}{$<0.001$} \\
\hline Primiparous & 1,387 & 0.42 & 0.03 & Reference & \\
\hline Multiparous & 1,757 & 0.31 & 0.02 & $0.62(0.53,0.73)$ & \\
\hline \multicolumn{5}{|l|}{ Season of $\mathrm{AI}^{3}$} & \multirow[t]{3}{*}{$<0.001$} \\
\hline Warm season & 1,130 & 0.33 & 0.02 & Reference & \\
\hline Cool season & 2.014 & 0.40 & 0.02 & $1.40(1.20,1.63)$ & \\
\hline \multicolumn{5}{|l|}{ Method of $\mathrm{AI}^{4}$} & \multirow[t]{3}{*}{0.047} \\
\hline AI after estrus & 413 & 0.34 & 0.03 & Reference & \\
\hline Timed AI & 2,731 & 0.39 & 0.02 & $1.26(1.00,1.59)$ & \\
\hline \multicolumn{5}{|l|}{ Mastitis risk groups ${ }^{5}$} & \multirow[t]{2}{*}{0.007} \\
\hline Healthy & 2,103 & 0.41 & 0.02 & Reference & \\
\hline Mastitis before BRP & 221 & 0.45 & 0.04 & $1.14(0.87,1.52)$ & 0.345 \\
\hline SM during BRP & 271 & 0.34 & 0.03 & $0.75(0.57,0.97)$ & 0.031 \\
\hline Chronic SM & 270 & 0.39 & 0.03 & $0.94(0.72,1.22)$ & 0.637 \\
\hline CM during BRP & 207 & 0.32 & 0.04 & $0.67(0.49,0.92)$ & 0.012 \\
\hline Chronic CM & 72 & 0.28 & 0.06 & $0.56(0.33,0.94)$ & 0.029 \\
\hline \multicolumn{6}{|l|}{ Interactions } \\
\hline \multicolumn{5}{|l|}{ Parity by season of AI } & \multirow[t]{2}{*}{0.022} \\
\hline Primiparous by cool season & & 0.44 & 0.03 & Reference & \\
\hline Primiparous by warm season & & 0.40 & 0.03 & $0.86(0.69,1.07)$ & 0.164 \\
\hline Multiparous by cool season & & 0.37 & 0.02 & $0.74(0.62,0.89)$ & 0.001 \\
\hline Multiparous by warm season & & 0.26 & 0.02 & $0.45(0.36,0.56)$ & $<0.001$ \\
\hline
\end{tabular}

${ }^{1}$ Number of samples, predictor least squares means (LSM), SEM, odds ratio (OR), and $P$-values are described for each variable. Missing values for mastitis status $(\mathrm{n}=20)$.

${ }^{2}$ Estimates of predicted probabilities of P/AI1 are described on the scale of the mean (inverse linked scale).

${ }^{3}$ Cool season (December to May), and warm season (June, July, August).

${ }^{4}$ Inseminations were categorized as occurring after a hormonal protocol for synchronization of ovulation (timed $\mathrm{AI})$ or after a detected estrus (AI after estrus).

${ }^{5}$ Subclinical during BRP (SM during BRP), clinical mastitis during BRP (CM during BRP), chronic subclinical mastitis (chronic SM), chronic clinical mastitis (chronic CM), mastitis before BRP, and healthy.

only evidence of mild CM in affected cows would be an increase in SCC, and this herd had the greatest prevalence $(16 \%)$ of cows classified in the mastitis risk group $\mathrm{SM}$ during the BRP. One of the greatest differences in $\mathrm{P} / \mathrm{AI} 1$ based on occurrence of $\mathrm{CM}$ was observed for this herd $(20 \% \mathrm{P} / \mathrm{AI} 1$ for cows experiencing CM vs. $39.1 \% \mathrm{P} / \mathrm{AI} 1$ for healthy cows). This observation may have occurred because fewer mild cases were included as CM events.

All farms assessed pregnancy status using transrectal ultrasonography beginning 27 to $32 \mathrm{~d}$ after AI. This method is known to be highly sensitive and specific (Fricke, 2002). Most pregnancy diagnoses were performed $32 \mathrm{~d}$ after AI by a single individual per farm and when inconclusive results were obtained, cows were re-examined 1 wk later. Thus, it is unlikely that misclassification of pregnancy status affected results of this study.

Differences in P/AI1 were associated with use of different breeding protocols. Overall, P/AI1 was greatest for cows that received TAI after a GGPG or a DoubleOvsynch protocol and least for cows that received TAI based on detection of estrus or after Presynch-Ovsynch
(Carvalho et al., 2014; Fricke et al., 2014). The use of different breeding protocols is common among commercial dairy farms and was unlikely to have influenced outcomes of this study. There is no reason to expect that the use of a particular breeding protocol was associated with mastitis risk, and there is no indication of confounding between breeding protocol and mastitis risk group. Thus, the use of different protocols did not influence study results and extends the inferences of this study beyond use of a single reproductive management program.

Barker et al. (1998) initially made a novel observation about the importance of the temporal association between occurrence of $\mathrm{CM}$ and reproductive performance, and defined the greatest risk period as immediately before AI or between AI and first pregnancy diagnosis. Further studies have confirmed that occurrence of mastitis during the period immediately before and after AI is associated with greater reductions in the probability of pregnancy as compared with mastitis that occurs earlier or later (Santos et al., 2004; Lavon et al., 2011a; Hudson et al., 2012). Based on other studies, the BRP of the current study was defined as $3 \mathrm{~d}$ before to $32 \mathrm{~d}$ 
Table 5. Final logistic regression model of association of severity of CM and pregnancies per AI at first AI (P/ AI1) after AI for 2,382 in 4 Wisconsin dairy herds ${ }^{1}$

\begin{tabular}{|c|c|c|c|c|c|}
\hline Variable & $\mathrm{n}$ & $\mathrm{LSM}^{2}$ & SEM & OR $(95 \% \mathrm{CI})$ & $P$-value \\
\hline Intercept & & -0.23 & 0.17 & & \multirow{4}{*}{$<0.001$} \\
\hline \multicolumn{5}{|l|}{ Parity } & \\
\hline Primiparous & 1,094 & 0.40 & 0.03 & Reference & \\
\hline Multiparous & 1,288 & 0.28 & 0.03 & $0.58(0.49,0.70)$ & \\
\hline \multicolumn{5}{|l|}{ Season of $\mathrm{AI}^{3}$} & \multirow[t]{3}{*}{0.001} \\
\hline Warm season & 838 & 0.30 & 0.03 & Reference & \\
\hline Cool season & 1,544 & 0.37 & 0.03 & $1.36(1.14,1.62)$ & \\
\hline \multicolumn{5}{|l|}{ Method of $\mathrm{AI}^{4}$} & \multirow[t]{3}{*}{0.089} \\
\hline AI after estrus & 294 & 0.31 & 0.04 & Reference & \\
\hline Timed AI & 2,088 & 0.36 & 0.03 & $1.26(0.97,1.65)$ & \\
\hline \multicolumn{5}{|l|}{ Severity of $\mathrm{CM}^{5}$} & \multirow[t]{2}{*}{0.004} \\
\hline Healthy & 2,103 & 0.41 & 0.02 & Reference & \\
\hline Mild & 171 & 0.33 & 0.04 & $0.71(0.50,0.99)$ & 0.045 \\
\hline Moderate-severe & 108 & 0.27 & 0.05 & $0.54(0.35,0.83)$ & 0.005 \\
\hline \multicolumn{6}{|l|}{ Interactions } \\
\hline \multicolumn{5}{|l|}{ Parity by season of AI } & 0.004 \\
\hline Primiparous by cool season & & 0.41 & 0.03 & Reference & \\
\hline Primiparous by warm season & & 0.40 & 0.04 & $0.95(0.74,1.22)$ & 0.700 \\
\hline Multiparous by cool season & & 0.34 & 0.03 & $0.76(0.61,0.93)$ & 0.008 \\
\hline Multiparous by warm season & & 0.23 & 0.03 & $0.43(0.33,0.56)$ & $<0.001$ \\
\hline
\end{tabular}

${ }^{1}$ Number of samples, predictor least squares means (LSM), SEM, odds ratio (OR), and $P$-values are described for each variable.

${ }^{2}$ Estimates of predicted probabilities of P/AI1 are described on the scale of the mean (inverse linked scale).

${ }^{3}$ Cool season (December to May), and warm season (June, July, August).

${ }^{4}$ Inseminations were categorized as occurring after a hormonal protocol for synchronization of ovulation (timed AI) or after a detected estrus (AI after estrus).

${ }^{5}$ Severity of CM events was defined as mild (abnormal milk only), moderate-severe (udder and systemic signs), and healthy (no mastitis before or during breeding risk period).

after the first AI, whereas the mastitis risk groups were used to separate the potentially differing effects of SM and CM that occurred outside of that window.

Similar to other studies (Santos et al., 2004; Lavon et al., 2011a; Hudson et al., 2012), the greatest reduction in the probability of pregnancy was associated with occurrence of $\mathrm{CM}$ or SM during the BRP. The probability of pregnancy for cows with chronic SM (SM or $\mathrm{CM}$ before the BRP and SM during the BRP) or mastitis before the BRP (either SM or CM) was not different from the probability of pregnancy for cows that remained healthy. The greatest decrease in the probability of pregnancy was observed for cows classified as having chronic CM (CM during the BRP that was preceded by either SM or CM before the BRP). The odds of pregnancy for these cows was reduced by almost half. The occurrence of SM or CM during the BRP only reduced the odds of pregnancy by about 25 and $33 \%$, respectively. Oliveira et al. (2013) reported that approximately $30 \%$ of first cases of CM occurred during the first $60 \mathrm{~d}$ after calving, immediately before the beginning of most programmed breeding periods. To maximize pregnancy rate, farmers need to recognize the effect that mastitis can have on P/AI1 and focus on preventing mastitis during this critical period.
Similar to Lavon et al. (2011a), the definition of SM used in the current study was based on a SCC threshold of $\geq 150,000$ cells $/ \mathrm{mL}$. This threshold was used for all parities even though a lower SCC threshold for first-lactation animals would have been more sensitive. Using this threshold, Lavon et al. (2011a) concluded that cows with chronic SM (defined as increased SCC at the test-dates before and after the breeding) had a reduced probability of conception as compared with uninfected or cured cows. They also concluded that cows with greater SCC (SCC $>10^{6}$ cells $/ \mathrm{mL}$ ) had the least probability of pregnancy. In the current study, cows in the category of chronic SM (defined as SM before and during the BRP) did not have reduced probability of pregnancy. However, Lavon et al. (2011a) used a large data set composed solely of SCC records without the inclusion of $\mathrm{CM}$ events. It is possible that results of the current study differed from Lavon et al. (2011a) because the most seriously affected chronic cows in the current study may have developed CM during the BRP, and were thus included in the chronic CM (defined in the current study as SM or CM before the BRP followed by CM during the BRP) group. Hudson et al. (2012) used data that included 6 categories of SCC and $\mathrm{CM}$ events to evaluate the relationship between 
Table 6. Final logistic regression model of association of etiology of CM and pregnancies per AI at first AI (P/AI1) after AI for 2,321 cows in 4 Wisconsin dairy herds ${ }^{1}$

\begin{tabular}{|c|c|c|c|c|c|}
\hline Variable & $\mathrm{n}$ & $\mathrm{LSM}^{2}$ & SEM & OR $(95 \% \mathrm{CI})$ & $P$-value \\
\hline Intercept & & -0.25 & 0.17 & & \\
\hline Parity & & & & & $<0.001$ \\
\hline Primiparous & 1,085 & 0.39 & 0.04 & Reference & \\
\hline Multiparous & 1,236 & 0.28 & 0.03 & $0.59(0.49,0.70)$ & \\
\hline Season of $\mathrm{AI}^{3}$ & & & & & 0.002 \\
\hline Warm season & 824 & 0.30 & 0.03 & Reference & \\
\hline Cool season & 1,497 & 0.36 & 0.03 & $1.33(1.11,1.59)$ & \\
\hline Method of $\mathrm{AI}^{4}$ & & & & & 0.059 \\
\hline AI after estrus & 288 & 0.30 & 0.04 & Reference & \\
\hline Timed AI & 2,033 & 0.36 & 0.03 & $1.30(0.99,1.71)$ & \\
\hline Etiology of $\mathrm{CM}^{5}$ & & & & & 0.029 \\
\hline Healthy & 2,103 & 0.41 & 0.02 & Reference & \\
\hline No growth & 92 & 0.40 & 0.06 & $0.94(0.61,1.46)$ & 0.795 \\
\hline Gram-positive & 73 & 0.29 & 0.06 & $0.58\left(\begin{array}{lll}0.35 & 0.97)\end{array}\right.$ & 0.036 \\
\hline Gram-negative & 53 & 0.25 & 0.06 & $0.48(0.25,0.91)$ & 0.025 \\
\hline Interactions & & & & & \\
\hline Parity by season of AI & & & & & 0.007 \\
\hline Primiparous by cool season & & 0.40 & 0.04 & Reference & \\
\hline Primiparous by warm season & & 0.39 & 0.04 & $0.96(0.75,1.23)$ & 0.758 \\
\hline Multiparous by cool season & & 0.33 & 0.03 & $0.75(0.61,0.93)$ & 0.007 \\
\hline Multiparous by warm season & & 0.23 & 0.03 & $0.44(0.34,0.58)$ & $<0.001$ \\
\hline
\end{tabular}

${ }^{1}$ Number of samples, predictor least squares means (LSM), SEM, odds ratio (OR), and $P$-values are described for each variable.

${ }^{2}$ Estimates of predicted probabilities of P/AI1 are described on the scale of the mean (inverse linked scale).

${ }^{3}$ Cool season (December to May), and warm season (June, July, August).

${ }^{4}$ Inseminations were categorized as occurring after a hormonal protocol for synchronization of ovulation (timed AI) or after a detected estrus (AI after estrus).

${ }^{5}$ Etiology of CM events were defined as gram-positive and gram-negative, no growth, and healthy (no mastitis occurring before or during breeding risk period). Sixty-one CM events were not included in the analysis because the etiology of those cases was not determined due to missing $(n=19)$, contaminated samples $(n=14)$, mixed cultures $(\mathrm{n}=15)$, nonbacterial infection causing CM (yeast, $\mathrm{n}=5)$, and excluded samples $(\mathrm{n}=8)$.

udder health and reproductive performance. The effect of SM on the probability of pregnancy was minimal until SCC exceeded 399,000 cells/mL (Hudson et al., 2012). Hudson et al. (2012) reported that the odds of pregnancy for cows with SCC of 100,000 to 199,000 cells/mL was $0.90(0.85-0.96)$ as compared with cows with SCC $<20,000$ cells/mL. Similarly, in the current study, the odds of pregnancy for cows defined as having chronic SM was $0.94(0.72-1.22)$, and it is likely that the current study lacked sufficient power to be able to detect a significant effect of that magnitude. Overall, it appears that SM can influence reproductive performance but that the magnitude of the effect increases with increased inflammation. It is evident that future research should be designed to account for the occurrence of both SM and CM events.

As compared with SM, CM is defined based on a more recognizable inflammatory response. The severity of CM symptoms is reflective of the amount of inflammation in response to specific characteristics of the pathogen, the magnitude of exposure to the pathogen, and the ability of the cow to rapidly respond to IMI (Burvenich et al., 1994). In this study, the distribution of mild, moderate, and severe cases of CM was about
$60 \%$ (mild), $27 \%$ (moderate), and $12 \%$ (severe) and was similar to previous reports (Pinzón-Sánchez and Ruegg, 2011; Oliveira et al., 2013). To the authors' knowledge, the association of severity of CM with probability of pregnancy has not been described. In the current study, as compared with healthy cows, the odds of pregnancy was reduced by about 30 and $50 \%$ for mild and moderate-severe cases of CM, respectively, but the $95 \%$ CI of those categories overlapped.

Cows that experience severe mastitis that is accompanied by systemic signs have a greater risk of developing serious systemic effects such as septicemia (Wenz et al., 2010). Vandeputte-Van Messom et al. (1993) categorized cows as moderate and severe responders to experimentally induced IMI caused by E. coli. Cows that were characterized as severe responders had systemic symptoms that were attributed to effects of LPS and delayed bacterial clearance due to a lower reactive oxygen species generating capacity and slower influx of neutrophils. In contrast, cows characterized as moderate responders had a rapid increase in SCC but shorter duration of systemic signs than severe responders. When CM is caused by gram-positive bacteria, the immune response is often milder and the case may not 
Table 7. Final logistic regression model of association of etiology and severity of CM and pregnancies per AI at first AI (P/AI1) after AI for 2,321 cows in 4 Wisconsin dairy herds ${ }^{1}$

\begin{tabular}{|c|c|c|c|c|c|}
\hline Variable & $\mathrm{n}$ & $\mathrm{LSM}^{2}$ & SEM & OR $(95 \% \mathrm{CI})$ & $P$-value \\
\hline Intercept & & -0.21 & 0.15 & & \\
\hline Parity & & & & & $<0.001$ \\
\hline Primiparous & 1,085 & 0.42 & 0.04 & Reference & \\
\hline Multiparous & 1,236 & 0.29 & 0.03 & $0.59(0.49,0.70)$ & \\
\hline Season of $\mathrm{AI}^{3}$ & & & & & 0.002 \\
\hline Warm season & 824 & 0.32 & 0.04 & Reference & \\
\hline Cool season & 1,497 & 0.39 & 0.04 & $1.33(1.11,1.59)$ & \\
\hline Method of $\mathrm{AI}^{4}$ & & & & & 0.054 \\
\hline AI after estrus & 288 & 0.32 & 0.04 & Reference & \\
\hline Timed AI & 2,033 & 0.38 & 0.04 & $1.31(1.00,1.71)$ & \\
\hline Etiology and severity of $\mathrm{CM}^{5}$ & & & & & 0.032 \\
\hline Healthy & 2,103 & 0.41 & 0.02 & Reference & \\
\hline No growth and mild & 75 & 0.39 & 0.06 & $0.90(0.56,1.46)$ & 0.679 \\
\hline No growth and moderate or severe & 17 & 0.44 & 0.12 & $1.14(0.43,3.00)$ & 0.797 \\
\hline GP and GN and mild & 59 & 0.33 & 0.06 & $0.72(0.42,1.25)$ & 0.245 \\
\hline GP and GN and moderate or severe & 67 & 0.22 & 0.05 & $0.41(0.23,0.72)$ & 0.002 \\
\hline Interactions & & & & & \\
\hline Parity by season of AI & & & & & 0.008 \\
\hline Primiparous by cool season & & 0.42 & 0.04 & Reference & \\
\hline Primiparous by warm season & & 0.41 & 0.05 & $0.95(0.74,1.22)$ & 0.711 \\
\hline Multiparous by cool season & & 0.35 & 0.04 & $0.75(0.61,0.92)$ & 0.007 \\
\hline Multiparous by warm season & & 0.24 & 0.04 & $0.44(0.34,0.57)$ & $<0.001$ \\
\hline
\end{tabular}

${ }^{1}$ Number of samples, predictor least squares means (LSM), SEM, odds ratio (OR), and $P$-values are described for each variable.

${ }^{2}$ Estimates of predicted probabilities of $\mathrm{P} / \mathrm{AI}$ are described on the scale of the mean (inverse linked scale).

${ }^{3}$ Cool season (December to May), and warm season (June, July, August).

${ }^{4}$ Inseminations were categorized as occurring after a hormonal protocol for synchronization of ovulation (timed AI) or after a detected estrus (AI after estrus).

${ }^{5}$ Etiology and severity of CM were combined into one variable with 5 categories. Sixty-one CM events were not included in the analysis because the etiology of those cases was not determined.

progress beyond the subclinical state (Schukken et al., 2011). Pathogen-specific immune responses are well recognized and probably account for much of the variation in case presentation (Bannerman et al., 2004a).

As reported for large US dairy farms (Pinzón-Sánchez and Ruegg, 2011; Oliveira and Ruegg, 2014; Hertl et al., 2010), the distribution of bacterial etiologies varied among farms but the majority of pathogens were of environmental origin. The magnitude of the effect of $\mathrm{SM}$ and $\mathrm{CM}$ on reducing reproductive performance probably varies among farms depending on prevalence of exposure to specific pathogens. Among the 4 farms enrolled in the current study, the prevalence of grampositive pathogens ranged from 15 to $33 \%$ of cases of $\mathrm{CM}$, the prevalence of gram-negative pathogens ranged from 12 to $36 \%$, and the prevalence of culture-negative results of milk samples ranged from 21 to $47 \%$. Whereas the majority of cases of CM present with mild or moderate symptoms, other studies have reported that severity of CM is associated with etiology. In a study of similar dairy herds in Wisconsin, mild cases of CM accounted for about $58 \%$ of both gram-positive and culturenegative cases of $\mathrm{CM}$ in contrast to only about $31 \%$ of gram-negative cases (Oliveira et al., 2013). About $35 \%$ of all etiologies were categorized with moderate symptoms, whereas severe cases were 3, 8, and $33 \%$ of gram-positive, culture-negative, and gram-negative etiologies, respectively. The distribution of pathogens has changed dramatically on modern dairy farms (Makovec and Ruegg, 2003), and results of the current study demonstrate that the effect of mastitis on reproduction varies among microbiological diagnoses.

As compared with healthy cows, the odds of pregnancy were reduced by about 40 to $50 \%$ for cows that experienced microbiologically positive cases of CM. Numerically, the greatest reduction in probability of pregnancy was for CM caused by gram-negative bacteria but the $95 \%$ CI overlapped with estimates of odds of pregnancy for gram-positive cases; however, this study had insufficient power to distinguish between the relatively small differences in P/AI1 observed between the gram-positive and gram-negative pathogens. Several other studies did not identify pathogen-specific effects of CM on outcomes such as days to first AI, services per conception, days open (Barker et al., 1998; Schrick et al., 2001), or conception rate (Santos et al., 2004). Other researchers (Moore et al., 1991; Hertl et al., 2010) have reported that the occurrence of gramnegative CM was associated with a greater reduction in the probability of pregnancy compared with IMI 
caused by other pathogens. However, without use of a standardized severity scoring system, it is possible that etiology could have been confounded by severity.

Culture-negative milk samples are typical microbiological results from about 25 to $40 \%$ of milk samples collected from cases of $\mathrm{CM}$ and from 40 to $70 \%$ of milk samples collected from cows with SM (Ruegg and Erskine, 2014). When adequate microbiological procedures are used, bacteriologically negative milk samples usually indicate that the immune system has either effectively eliminated the IMI or, alternatively, has decreased the number of bacteria to below normal laboratory detection limits (Ruegg and Erskine, 2014). Although several studies have examined pathogen-specific effects of $\mathrm{CM}$ on reproductive outcomes (Barker et al., 1998; Schrick et al., 2001; Santos et al., 2004; Hertl et al., 2010), no studies have assessed the effect of bacteriologically negative CM cases, and the results reported herein are novel findings. Most studies that examine immune responses of cows to IMI are challenge studies using specific pathogens, and no studies have specifically defined the immune response of cows that experience $\mathrm{CM}$ in which no bacteria have been recovered. However, compared with culture-positive cases of $\mathrm{CM}$, favorable clinical outcomes of culture-negative cases are often observed (Oliveira et al., 2013).

The results of the current study support the difference and greater magnitude of the innate immune response due to gram-negative bacterial IMI (Bannerman, 2009). The effect and severity of mastitis caused by gram-negative and gram-positive bacteria observed in the current study support the hypothesis that probability of pregnancy is likely associated with pathogenspecific immune mechanisms; however, more research in this area is needed. In the current study, cases of $\mathrm{CM}$ that were culture-negative did not have reduced probability of pregnancy. In those cases, the innate immune response may have reacted so rapidly, effectively, and briefly that it eliminated the pathogen or reduced the number of bacteria without causing pronounced inflammation, thereby reducing the effect of circulating inflammatory mediators or changes in metabolites during the infection that could affect ovarian function (Price et al., 2013). Characteristics of SCC responses before and after a case of CM have been reported to be similar for CM caused by E. coli and culture-negative cases (de Haas et al., 2002). In both instances the SCC increased rapidly before the CM event and rapidly returned to a normal level after the case resolved (de Haas et al., 2002). It is conceivable that in some instances, a rapid and successful immune response to IMI may not initiate sufficient inflammation to result in disruptions of reproductive performance, and future research should be focused on better understanding of these mechanisms.

In the current study, cows that experienced culturenegative cases of $\mathrm{CM}$ had no reduction in the probability of pregnancy as compared with healthy cows. However, when bacteria were recovered from moderatesevere cases of CM cases, the probability of pregnancy was considerably reduced. These data suggest that the magnitude of the immune response is more important than etiology. Characteristics of the cow that influence the rapidity, effectiveness, and duration of the innate immune response may explain differences in the effect of CM on conception (Vandeputte-Van Messom et al., 1993). More research is needed to differentiate factors that influence the speed and effective of clearance of IMI caused by a variety of pathogens.

\section{CONCLUSIONS}

On 4 large dairy herds in Wisconsin, cows experiencing SM and CM during the BRP and chronic CM had a reduced probability of pregnancy compared with healthy cows. In agreement with other studies, the occurrence of mastitis during the immediate BRP had the most detrimental effect on probability of pregnancy. A dose-response effect was observed based on severity of $\mathrm{CM}$ cases. As cases progressed from mild to moderatesevere, the probability of pregnancy decreased. Moderate-severe, microbiologically positive cases of $\mathrm{CM}$ were associated with the greatest reduction in $\mathrm{P} / \mathrm{AI} 1$, but no difference was found in P/AI1 between gram-positive and gram-negative pathogens. Regardless of the severity of the inflammatory response, cows that experience CM caused by culture-negative bacteria did not have a reduction in the probability of pregnancy. Characterization of CM by etiology and severity is important to evaluate the probability of success of first AI.

\section{ACKNOWLEDGMENTS}

This study was supported by USDA Agriculture and Food Research Initiative (AFRI, Washington, DC) Competitive Grant no. 2010-85122-20612.

\section{REFERENCES}

Ahmadzadeh, A., F. Frago, B. Shafii, J. C. Dalton, W. J. Price, and M. A. McGuire. 2009. Effect of clinical mastitis and other diseases on reproductive performance of Holstein cows. Anim. Reprod. Sci. 112:273-282.

Bannerman, D. D. 2009. Pathogen-dependent induction of cytokines and other soluble inflammatory mediators during intramammary infection of dairy cows. J. Anim. Sci. 87:10-25.

Bannerman, D. D., M. J. Paape, J. P. Goff, K. Kimura, J. D. Lippolis, and J. C. Hope. 2004a. Innate immune response to intramammary 
infection with Serratia marcescens and Streptococcus uberis. Vet. Res. 35:681-700.

Barker, A. R., F. N. Schrick, M. J. Lewis, H. H. Dowlen, and S. P. Oliver. 1998. Influence of clinical mastitis during early lactation on reproductive performance of jersey cows. J. Dairy Sci. 81:1285-1290.

Burvenich, C., M. J. Paape, A. W. Hill, A. J. Guidry, R. H. Miller, R. Heyneman, W. D. J. Kremer, and A. Brand. 1994. Role of the neutrophil leucocyte in the local and systemic reactions during experimentally induced E. coli mastitis in cows immediately after calving. Vet. Q. 16:45-50.

Caraviello, D. Z., K. A. Weigel, P. M. Fricke, M. C. Wiltbank, M. J. Florent, N. B. Cook, K. V. Nordlund, N. R. Zwald, and C. L. Rawson. 2006. Survey of management practices on reproductive performance of dairy cattle on large US commercial farms. J. Dairy Sci. 89:4723-4735.

Carvalho, P. D., J. N. Guenther, M. J. Fuenzalida, M. C. Amundson, M. C. Wiltbank, and P. M. Fricke. 2014. Presynchronization using a modified Ovsynch protocol or a single GnRH injection $7 \mathrm{~d}$ before an Ovsynch-56 protocol for submission of lactating dairy cows for first timed artificial insemination. J. Dairy Sci. 97:6305-6315.

Chebel, R. C., J. E. P. Santos, J. P. Reynolds, R. L. A. Cerri, S. O. Juchem, and M. Overton. 2004. Factors affecting conception rate after artificial insemination and pregnancy loss in lactating dairy cows. Anim. Reprod. Sci. 84:239-255.

de Haas, Y., H. W. Barkema, and R. F. Veerkamp. 2002. The effect of pathogen-specific clinical mastitis on the lactation curve for somatic cell count. J. Dairy Sci. 85:1314-1323.

Dohoo, I. R., and A. H. Meek. 1982. Somatic cell counts in bovine milk. Can. Vet. J. 23:119-125.

Fricke, P. M. 2002. Scanning the future - Ultrasonography as a reproductive management tool for dairy cattle. J. Dairy Sci. 85:19181926.

Fricke, P. M., J. O. Giordano, A. Valenza, G. Lopes Jr., M. C. Amundson, and P. D. Carvalho. 2014. Reproductive performance of lactating dairy cows managed for first service using timed artificial insemination with or without detection of estrus using an activitymonitoring system. J. Dairy Sci. 97:2771-2781.

Giordano, J. O., M. C. Wiltbank, J. N. Guenther, M. S. Ares, G. Lopes Jr., M. M. Herlihy, and P. M. Fricke. 2012. Effect of presynchronization with human chorionic gonadotropin or gonadotropinreleasing hormone 7 days before resynchronization of ovulation on fertility in lactating dairy cows. J. Dairy Sci. 95:5612-5625.

Hertl, J. A., Y. T. Gröhn, J. D. G. Leach, D. Bar, G. J. Bennett, R. N. González, B. J. Rauch, F. L. Welcome, L. W. Tauer, and Y. H. Schukken. 2010. Effects of clinical mastitis caused by grampositive and gram-negative bacteria and other organisms on the probability of conception in New York State Holstein dairy cows. J. Dairy Sci. 93:1551-1560.

Hudson, C. D., A. J. Bradley, J. E. Breen, and M. J. Green. 2012. Associations between udder health and reproductive performance in United Kingdom dairy cows. J. Dairy Sci. 95:3683-3697.

Lavon, Y., E. Ezra, G. Leitner, and D. Wolfenson. 2011a. Association of conception rate with pattern and level of somatic cell count elevation relative to time of insemination in dairy cows. J. Dairy Sci. 94:4538-4545.

Lavon, Y., G. Leitner, E. Klipper, U. Moallem, R. Meidan, and D. Wolfenson. 2011b. Subclinical, chronic intramammary infection lowers steroid concentrations and gene expression in bovine preovulatory follicles. Domest. Anim. Endocrinol. 40:98-109.

Makovec, J. A., and P. L. Ruegg. 2003. Characteristics of milk samples submitted for microbiological examination in Wisconsin from 1994 to 2001. J. Dairy Sci. 86:3466-3472.

Moore, D. A., J. S. Cullor, R. H. Bondurant, and W. M. Sischo. 1991. Preliminary field evidence for the association of clinical mastitis with altered intervals in dairy cattle. Theriogenology 36:257-265.
Moreira, F., C. Orlandi, C. A. Risco, R. Mattos, F. Lopes, and W. W. Thatcher. 2001. Effect of presynchronization and bovine somatotropin on pregnancy rates to a timed artificial insemination protocol in lactating dairy cows. J. Dairy Sci. 84:1646-1659.

National Mastitis Council. 1999. Laboratory Handbook on Bovine Mastitis. National Mastitis Council, Verona, WI.

Norman, H. D., and L. M. Walton. 2013. Somatic cell counts of milk Dairy Herd Improvement herds during 2013. Accessed Jun. 9, 2014. https://www.cdcb.us/publish/dhi/current/sccx.html.

Oliveira, L., C. Hulland, and P. L. Ruegg. 2013. Characterization of clinical mastitis occurring in cows on 50 large dairy herds in Wisconsin. J. Dairy Sci. 96:7538-7549.

Oliveira, L., and P. L. Ruegg. 2014. Treatments of clinical mastitis occurring in cows on 51 large dairy herds in Wisconsin. J. Dairy Sci. 97:5426-5436.

Pinzón-Sánchez, C., and P. L. Ruegg. 2011. Risk factors associated with short-term post-treatment outcomes of clinical mastitis. J. Dairy Sci. 94:3397-3410.

Price, J. C., J. J. Bromfield, and I. M. Sheldon. 2013. Pathogenassociated molecular patterns initiate inflammation and perturb the endocrine function of bovine granulosa cells from ovarian dominant follicles via TLR2 and TLR4 pathways. Endocrinology 154:3377-3386

Pursley, J. R., M. O. Mee, and M. C. Wiltbank. 1995. Synchronization of ovulation in dairy cows using $\mathrm{PGF}_{2 \alpha}$ and $\mathrm{GnRH}$. Theriogenology 44:915-923.

Risco, C. A., G. A. Donovan, and J. Hernandez. 1999. Clinical mastitis associated with abortion in dairy cows. J. Dairy Sci. 82:16841689.

Ruegg, P. L. 2012. New perspectives in udder health management. Vet. Clin. North Am. Food Anim. Pract. 28:149-163.

Ruegg, P. L., and R. J. Erskine. 2014. Mammary Gland Health. Pages 1015-1043 in Large Animal Internal Medicine. 5th ed. Mosby Elsevier, St. Louis, MO.

Santos, J. E. P., R. L. A. Cerri, M. A. Ballou, G. E. Higginbotham, and J. H. Kirk. 2004. Effect of timing of first clinical mastitis occurrence on lactational and reproductive performance of Holstein dairy cows. Anim. Reprod. Sci. 80:31-45.

SAS Institute. 2011. SAS/STAT User's Guide. Version 9.3 SAS Institute Inc., Cary, NC.

Schrick, F. N., M. E. Hockett, A. M. Saxton, M. J. Lewis, H. H. Dowlen, and S. P. Oliver. 2001. Influence of subclinical mastitis during early lactation on reproductive performance. J. Dairy Sci. 84:1407-1412.

SchukkenY. H.GuntherJ.FitzpatrickJ.FontaineM. C.GoetzeL.HolstO. LeighJ.PetzlW.SchuberthH. -J.SipkaA.SmithD. G. E.QuesnellR. WattsJ.YanceyR.ZerbeH.GurjarA.ZadoksR. N.SeyfertH. -M.members of the Pfizer mastitis research consortium. 2011. Host-response patterns of intramammary infections in dairy cows. Vet. Immunol. Immunopathol. 144:270-289.

Souza, A. H., H. Ayres, R. M. Ferreira, and M. C. Wiltbank. 2008. A new presynchronization system (Double-Ovsynch) increases fertility at first postpartum timed AI in lactating dairy cows. Theriogenology 70:208-215.

Vandeputte-Van Messom, G., C. Burvenich, E. Roets, A. M. MassartLeën, R. Heyneman, W. D. Kremer, and A. Brand. 1993. Classification of newly calved cows into moderate and severe responders to experimentally induced Escherichia coli mastitis. J. Dairy Res. 60:19-29.

Wenz, J. R., L. K. Fox, F. J. Muller, M. Rinaldi, R. Zeng, and D. D. Bannerman. 2010. Factors associated with concentrations of select cytokine and acute phase proteins in dairy cows with naturally occurring clinical mastitis. J. Dairy Sci. 93:2458-2470. 